\title{
Efficacy of different oils used for the extraction of annatto colour from the seeds of Bixa orellana $\mathbf{L}$.
}

\author{
A. A. Mehta*, L. K. Behera, M. B. Tandel, D. B. Jadeja and B. G. Vashi \\ College of Forestry, Navsari Agricultural University, Navsari- 396450 (Gujarat), INDIA \\ *Corresponding author. E-mail: aamehta@nau.in \\ Received: January 8, 2015; Revised received: August 18, 2015; Accepted: October 15, 2015
}

\begin{abstract}
Annatto, a naturally obtained colour is a potential and valuable Non Wood Forest Product (NWFP). It is obtained from the seeds of plant species Bixa orellana $\mathrm{L}$. The present experiment was carried out to find the efficacy of different oils used for annatto colour extraction. Experiment was started with the pretreatment of seeds of B. orellana with soaking in water at $0 \%, 50 \%, 100 \%$ and $150 \%(\mathrm{v} / \mathrm{w})$ for $24 \mathrm{hrs}$ at room temperature and colour extraction with castor oil at $100^{\circ} \mathrm{C}$ showed that maximum bixin (\%) was found from the pretreated seeds with $50 \%$ (v/w) water soaking i.e., $0.46 \%$ bixin. Similarly for oil soluble annatto extraction method, the maximum extraction of bixin $(0.99 \%)$ was found with castor oil at $120^{\circ} \mathrm{C}$ for $1 \mathrm{hr}$ and least bixin $(0.03 \%)$ was recorded with mustard oil at $60^{\circ} \mathrm{C}$ temperature for $1 \mathrm{hr}$. Sesame oil and ground nut oil were also showed better extractability. Out of different treatments, castor oil at $120^{\circ} \mathrm{C}$ for $1 \mathrm{hr}$ gave better result with respect to bixin extraction as compared to others.
\end{abstract}

Keywords: Annatto, Bixa orellana, Bixin, Oil extraction, Temperature

\section{INTRODUCTION}

Bixa orellana L, popularly known as lipstick tree belongs to Bixaceae family. This is a small tree or shrub of two to five meters tall and native to tropical America. This plant is naturally occurring in the forests of Western Ghats and also in some part of Gujarat. It is widely cultivated in southern part of India. Seeds of this plant are covered with a resinous orange or red coating (arils) from which the commercial pigment bixin is extracted known as annatto (FAO, 2006). The pigments are located in the pericarp of the seeds and have two main components: oil-soluble bixin and water-soluble norbixin (Chao et al., 1991). Annatto has a widespread use in the food industry. It is often blended with other ingredients for addition to soups and meat dishes similar to the use of paprika seasonings in Europe. Formulations of annatto is used in ice cream, soup, confectionery, dairy products, juices, liqueurs, transparent jellies and gelatinous desserts, sausage casing, sausages, puddings, tomato sauce, breakfast cereals, butter milk desserts, chocolate fillings, smoked fish and pet food (FAO, 2006). The pigments of the annatto seeds bixin and norbixin are amongst those most used in the food, pharmacological and cosmetic industries due to the intensity of their colours, their greater stability and the wide variety of tones from yellow, orange to red. This range of colours is an additional advantage of the annatto carotenoids over other carotenoids, such as those of the carrot and beetroot, which only show their respective colours. Dye from annatto seeds can be used as dyeing agent for coloring textile fibers like cotton, wool, silk and for making colorful "Gulal" (Saha and Sinha, 2012). Swati et al. (2013) formulated an herbal lipstick from annatto having minimal or no side effects.

Annatto formulations are generally available as oil or water-soluble solutions, suspensions, emulsions, encapsulated products, and spray-dried powders with carriers (Scotter et al., 1998). Oil based annatto preparations are mainly used to colour foods with high fat content, such as butter, oils, margarine or processed cheese, yoghurt, creams. These are also extensively used in bakery products, sauces, biscuit filling, popcorn, snack foods, dressings, and desserts and also in pharmacy, dyeing of leather and cosmetics with hues ranging from yellow to red (Coulson, 1980; Chao et al., 1991 and Scotter et al., 1998). Due to toxic and health related issues of synthetic dyes and increasing legislative restrictions on the use of synthetic dye stuffs, there is a great demand of nonhazardous natural dyes like annatto, saffron, turmeric etc. in food industries. Besides increasing consumer awareness regarding their health and quality food stuff, the uses of natural dyes in foods will rise in the near future. Many workers have reviewed the health problems due to prolonged use of synthetic dyes like indigestion, anaemia, pathological lesions in the brain, spleen, kidney, liver and tumours, cancer, paralysis, growth retardation and eye defects leading to blindness, etc. (Goyle and Gupta, 1998 and Rao et al., 2004). Commercial extract of oil soluble annatto pigments are obtained from the seeds by several processes such as 
suspension in oil, mechanical processes and solvent extraction (Preston and Rickard, 1980 and Degnan et al., 1991). The commercial preparations of annatto colours with organic solvents have inconvenient of small concentration of pigments and residual toxic solvent in the product (Mckeown and Mark, 1962 and Preston and Rickard, 1980). With respect to food applications, directly extracted oil soluble annatto is better than the annatto extracted with the help of organic solvents like chloroform due to residual effects of particular solvent. With the view of importance of annatto, present study was conducted with the objective to find out the efficacy of different oils used for the extraction of annatto colour from the seeds of B. orellana.

\section{MATERIALS AND METHODS}

The present study was conducted at Soil Chemistry Laboratory, ASPEE College of Horticulture and Forestry. Seeds collected from Navsari Agriculture University (NAU), Navsari and Dapoli, Maharashtra were taken for preliminary analysis of bixin (\%) content which was done by $\mathrm{KOH}$ method as suggested by Verissimo et al. (2003). The maximum bixin content was found in the seeds of Dapoli $(1.75 \%)$ as compared to seeds of NAU, Navsari(1.69\%). After that seeds from Dapoli having maximum bixin content as compared to NAU were considered for annatto extraction by using different types of oil. There were two methods used for extraction of annatto having oil as common. In the first method, the cleaned seeds were soaked in distilled water for $24 \mathrm{hrs}$ at room temperature $\left(27-30^{\circ} \mathrm{C}\right)$ before its extraction in castor oil. The volumes of water used for soaking the seeds were 0 , 50,100 and 150 of the seeds mass and water level was conveniently expressed as per cent $(\mathrm{v} / \mathrm{w})$ and denoted by the treatment S1, S2, S3 and S4 respectively (Table 1). For extraction of colour, the water treated seeds were taken in castor oil $(10 \mathrm{~g}$ seeds into $50 \mathrm{ml}$ oil) and temperature was set at $100^{\circ} \mathrm{C}$ for $1 \mathrm{hr}$. Determinations of bixin content was done as per the method described by FAO (FAO, 1982 and 2006). In the second method, vegetable oils that are listed as edible oil in the Prevention of Food Adulteration (PFA) rules (except castor oil) and commonly available in the local market were collected like castor oil, ground nut oil, cotton oil,

Table 1. Effect of water soaking of annatto seeds on bixin content with castor oil extract.

\begin{tabular}{ll}
\hline Amount of water \% (v/w)of seeds & Bixin\% \\
\hline S1 $=00(0 \mathrm{ml}$ water +10 g seeds $)$ & 0.40 \\
S2 $=50(500 \mathrm{ml}$ water +10 g seeds $)$ & 0.46 \\
S3 $=100(1000 \mathrm{ml}$ water +10 g seeds $)$ & 0.44 \\
S4 $=150(1500 \mathrm{ml}$ water +10 g seeds $)$ & 0.41 \\
S. Em. \pm & 0.008 \\
C. D. at $5 \%$ & 0.03 \\
C. V. & 3.97 \\
\hline
\end{tabular}

mustard oil and sesamum oil for the requirement of the study. Oils were collected from the freshly opened packs. Accurately weighed $10 \mathrm{~g}$ seeds were added to $50 \mathrm{ml}$ different type of oil and kept in temperature of room temperature for $16 \mathrm{hrs}$ or put in to the oven at required temperature $\left(60^{\circ} \mathrm{C}, 90^{\circ} \mathrm{C}, 120^{\circ} \mathrm{C}\right.$, etc. $)$ for $1 \mathrm{hr}$. Treatments of various oil are denoted as $\mathrm{C} 1=$ Castor oil; $\mathrm{C} 2=$ Ground nut oil; $\mathrm{C} 3=$ Cotton oil; $\mathrm{C} 4=$ Mustard oil and $\mathrm{C} 5=$ Sesamum oil and treatments of temperature are denoted as $\mathrm{T} 1=$ room temperature for $16 \mathrm{hr}$; $\mathrm{T} 2=60{ }^{\circ} \mathrm{C}$ for $1 \mathrm{hr} ; \mathrm{T} 3=90{ }^{\circ} \mathrm{C}$ for $1 \mathrm{hr} ; \mathrm{T} 4=120^{\circ} \mathrm{C}$ for $1 \mathrm{hr}$ and $\mathrm{T} 5=130^{\circ} \mathrm{C}$ for $1 \mathrm{hr}$. After shaking well for 15 minutes in mechanical shaker for better extraction then oil was cooled to room temperature and filtered with filter paper. Finally it was stored in dry vessels. Annatto colour extraction in oil was done as per the method suggested by Castello et al. (2004). The absorbance was measured at wave length of $470 \mathrm{~nm}$ by UV spectrometer. Determination of bixin percentage was done as per the methods described by FAO (FAO, 1982 and 2006). The experimental data of all the characters studied were subjected to the statistical analysis for proper interpretation. Analysis of variance was used for analyzing the data appropriate to the Completely Randomized Design (CRD) of the experiment and test of significance suggested by Panse and Sukhatme (1967).

\section{RESULTS AND DISCUSSION}

The first and crucial step in this investigation was to select seeds of B. orellana from the available localities. Seeds from both localities (NAU, Navsari and Dapoli, Maharashtra) were tested for their bixin content in the seeds as preliminary test. The result showed that seeds of Dapoli contain higher amount of bixin (1.75\%). It may be due to cultivation practices and climatic effects. Balaswamy et al. (2006) had found 1.00 to 1.69 $\%$ bixin whereas Silva et al. (2008) had found $2.7 \%$ bixin in the seeds of annatto. This finding was supported by Castello et al. (2004) where they studied effect of location in pigment extraction from annatto seeds. They found maximum bixin in caster oil from the seeds of Dapoli $(0.81 \%)$ as compared to Kolad $(0.75 \%)$. Though in that study, they have not analyzed the bixin content in the seeds, but they have studied the bixin content in oil which is used for pigment extraction from the seeds of different location. The quality of seeds and their geographical condition has influence on annatto dye yield as evident from various reports wherein, the seeds from Peru are the best with 3-4\% bixin content (Giridhar et al., 2014). In the first method, the water soaking of seeds had significant effect on bixin content of the extracts (Table 1). The significantly higher extraction $(0.46 \%)$ could be found with $50 \%$ water soaking. Further data also indicate that there was decrease in the bixin content when water soaking was more than $50 \%(\mathrm{v} / \mathrm{w})$ of seeds mass. This may be due to the behaviour of pretreatment inspired 
Table 2. Interaction effect of different oil and temperature treatments for annatto extraction (bixin \%).

\begin{tabular}{lcccccc}
\hline \multirow{2}{*}{ Oil Treatment } & \multicolumn{7}{c}{ Temperature levels } & Mean \\
\cline { 2 - 6 } & T1 & T2 & T3 & T4 & T5 & 0.486 \\
C1 & 0.13 & 0.08 & 0.28 & 0.99 & 0.95 & 0.406 \\
C2 & 0.15 & 0.09 & 0.21 & 0.83 & 0.75 & 0.346 \\
C3 & 0.13 & 0.06 & 0.17 & 0.74 & 0.63 & 0.366 \\
C4 & 0.04 & 0.03 & 0.17 & 0.80 & 0.79 & 0.440 \\
C5 & 0.12 & 0.09 & 0.32 & 0.85 & 0.82 & \\
Mean & 0.114 & 0.070 & 0.230 & 0.842 & 0.788 & \\
S. Em. \pm & & 0.012 & & & \\
C. D. at 5\% & & 0.04 & & & \\
\hline
\end{tabular}

$\mathrm{C} 1=$ Castor oil; $\mathrm{C} 2=$ Ground nut oil; $\mathrm{C} 3=\mathrm{Cotton}$ oil; $\mathrm{C} 4=$ Mustard oil; $\mathrm{C} 5=$ Sesamum oil; $\mathrm{T} 1=$ room temperature for $16 \mathrm{hr}$; $\mathrm{T} 2=60{ }^{\circ} \mathrm{C}$ for $1 \mathrm{hr}$; $33=90^{\circ} \mathrm{C}$ for $1 \mathrm{hr}$; $\mathrm{T} 4=120^{\circ} \mathrm{C}$ for $1 \mathrm{hr}$; T $5=130^{\circ} \mathrm{C}$ for $1 \mathrm{hr}$

to postulate that two phenomena (a) loosening of the pigment coat and (b) cooling due to water evaporation might be operating simultaneously during the extraction process. The phenomenon (a) accelerated pigment extraction whereas (b) slowed downs it by lowering temperature of seed-oil mixture and consequently a net effect was reflected (Gojiya, 2005). Barnett and Espoy (1957) had included water-soaking treatment in their patented process for extraction of colouring matter from annatto seeds. Murthi et al. (1989) have reported that the wetting of annatto seeds to $20 \%$ total moisture for one hour before extraction raised yellow units of the extract from 5 to 15 and 4 to 8 upon extraction with refined groundnut oil at $90^{\circ} \mathrm{C}$ and $120^{\circ} \mathrm{C}$, respectively. Present study also confirms the benefits of water soaking of annatto seeds prior its extraction in castor oil. In the second method, castor oil significantly extract higher bixin $(0.99 \%)$ at treatment $\mathrm{T} 4 \mathrm{C} 1 \quad\left(120^{\circ} \mathrm{C}\right.$ temperature for $1 \mathrm{hr}$ with castor oil) followed by treatment $\mathrm{T} 5 \mathrm{C} 1\left(130^{\circ} \mathrm{C}\right.$ temperature for $1 \mathrm{hr}$ with castor oil) which is $0.95 \%$ and least percentage of bixin $(0.03 \%)$ was recorded in $\mathrm{T} 2 \mathrm{C} 4\left(60^{\circ} \mathrm{C}\right.$ temperature for $1 \mathrm{hr}$ with mustard oil). It has been observed that as the temperature rises, bixin extraction is also increases. FAO (2006) reported that direct extraction with vegetable oil contain less than $1 \% \mathrm{w} / \mathrm{w}$ bixin because bixin is soluble to limited extent in vegetable oil, it is possible to obtain oil solutions of annatto whereby the final colour content is less than $1 \% \mathrm{w} / \mathrm{w}$. Considering oil type irrespective of temperature treatments, maximum bixin content in castor oil $(0.49 \%)$ followed by sesame oil $(0.44 \%)$ and least in cotton seed oil (0.34\%). Castello et al. (2004) reported $0.81 \%$ and $0.75 \%$ of bixin when extracted by castor oil from seeds of B. orellana from Kolad and Dapoli region respectively. Similarly in case of temperature variation irrespective of oil treatments, maximum bixin content $(0.84 \%)$ was found at $120 \mathrm{oC}$ temperature for $1 \mathrm{hr}$, followed by $130^{\circ} \mathrm{C}$ for $1 \mathrm{hr}(0.79 \%)$ and the lowest percentage of bixin $(0.07 \%)$ was noted in $60^{\circ} \mathrm{C}$ for $1 \mathrm{hr}$. According to FAO/WHO (1970), the temperature during extraction of pigment from the seeds, using oil or aqueous alkali should not be more than $130^{\circ} \mathrm{C}$. Murthi et al. (1989) reported $90^{\circ} \mathrm{C}$ for castor oil and $120^{\circ} \mathrm{C}$ for groundnut oil as the extractant for maximum colour intensity. However the pigment content in the oil was not quantified. Further, results showed that higher temperature gives better result in limited extent. It may be due to increase in movement of oil particles, increase the solubility of oil. After some higher temperature, the degradation of colour starts. The degradation or structural modification of the bixin is accompanied by the release of m-xylene, toluene, toluic acid and methyl ester, all of which are undesirable in preparations intended for food use (Gloria et $a l .$, 1995). Though castor oil show the maximum extractability but by consideration of the edibility and the price in the market, other oils like sesamum oil and ground nut oil which show better extractability after castor oil, can be used for various food applications.

\section{Conclusion}

It was concluded that for extraction of annatto, the seeds soaked in $50 \%(\mathrm{v} / \mathrm{w})$ water for 24 hours at room temperature and colour extraction with castor oil at $100^{\circ} \mathrm{C}$ showed maximum bixin $(0.46 \%)$. Similarly for oil soluble annatto extraction method, the maximum extraction of bixin was found in castor oil at $120^{\circ} \mathrm{C}$ for $1 \mathrm{hr}$ i.e. $0.99 \%$ and least percentage of $0.03 \%$ was recorded at $60^{\circ} \mathrm{C}$ temperature for $1 \mathrm{hr}$ with mustard oil. Out of different treatments, castor oil at $120^{\circ} \mathrm{C}$ for $1 \mathrm{hr}$ gave better result with respect to bixin extraction as compared to others. Considering the edibility and extractability, oils like sesamum oil and ground nut oil can be used for pigment extraction in commercial food applications.

\section{REFERENCES}

Barnett, M.B. and Espoy, H.M. (1957). Extracting colouring matter from annatto seeds. U.S. Patent 2815287 A.

Balaswamy, K., Rao, P.G.P., Satyanarayana, A., Rao, D.G. (2006). Stability of bixin in annatto oleoresin and dye powder during storage. LWT-Food Science and Technology, 39: 952-956.

Castello, M., Chandra, C., Pathak, A. and Sharon, M. (2004). Estimation of bixin in seeds of Bixa orellana L. from different location in western Maharashtra. Indian Journal of Plant Physiology, 9 (2):185-188.

Chao, R.R., Mulvaney S.J., Sanson D.R., Hsieh F. and Tem- 
pesta M. S. (1991). Supercritical CO2 Extraction of Annatto (Bixa orellana) Pigments and Some Characteristics of the Color Extracts. Journal of Food Science, 56 (1): 80-83.

Coulson, J. (1980). Miscellaneous naturally occurring colouring materials for foodstuffs. In Developments in Food Colours-1 (Walford, J. Ed.). Applied science publishers Ltd., London. 189-218.

Degnan, A.J., Elba, J.H.V. and Hartel, R.W. (1991). Extraction of annatto seed pigment by supercritical carbon dioxide. Journal of Food Science, 56 (6): 1655-1659.

FAO (1982). Annatto extracts. In Specifications for the identity and purity of certain food additives. In FAO food and nutrition paper no. - 25, FAO, Rome. $15-23$.

FAO (2006). Annatto extracts: chemical and technical assessment, in: 67th Joint FAO/WHO Expert Committee on Food Additives, Rome, Italy, 2006. Available in: $\mathrm{ftp} / / / \mathrm{ftp}$. fao.org/ag/agn/jecfa/ctaannatto.pdf.

FAO/WHO (1970). Specifications for the identity and purity of some food colours, emulsifiers, stabilizers, anticaking agents and certain other food additives. 13th Report of Joint FAD/WHO Expert Committee on Food Additives, Geneva.

Giridhar, P., Venugopalan, A. and Parimalan, R. (2014). A Review on Annatto Dye Extraction, Analysis and Processing - A Food Technology Perspective. Journal of Scientific Research \& Reports, 3(2): 327-348.

Gloria, M.B.A., Vale, S.R. and Bobbio, P.A. (1995). Effect of water activity on the stability of bixin in annatto extract-microcrystalline cellulose model system. Food Chemisty, 52: 389-391.

Gojiya, N.S. (2005). Studies on preparation and properties of Oil-soluble Annatto Colour for food. Ph.D. Thesis submitted to Anand Agricultural University, Anand (Gujarat), India.

Goyle, A. and Gupta, G. (1998). Use of synthetic colours in foods. Science and Culture, 64(11/12): 241-243.

McKeown, G. G. and Mark, E. (1962). The composition of oil-soluble annatto food colors. Journal of the Association of Official Analytical Chemists, 45 (3): 761-766.

Murthi, T.N., Devdhara, V.D., Punjrath, J.S. and Aneja, R.P.
(1989). Extraction of annatto colours from the seeds of Bixa orellana using edible oils. Indian Journal of Dairy Science, 42: 750-756.

Panse, V.G. and Sukhatme, P.V. (1967). Statistical Methods for Agricultural Workers. 2nd Edition, ICAR publication, New Delhi.

Preston, H. D. and Rickard, M. D. (1980). Extraction and chemistry of annatto. Food Chemistry, 5:47-56.

Rao, P.G.P., Jyothirmayi, T., Balaswamy, K., Satyanarayana, A. and Rao, D.G. (2004). Effect of processing conditions on the stability of annatto (Bixa orellana L.) dye incorporated into some foods. LWT - Food Science and Technology, 38: 779-784.

Saha, P. D. and Sinha, K. (2012). Natural dye from bixa seeds as a potential alternative to synthetic dyes for use in textile industry. Desalination and Water Treatment, 40(1-3):298-301.

Scotter, M. J., Wilson, L. A., Appleton, G. P., and Castle, L. (1998). Analysis of annatto (Bixa orellana) food colouring formulations. 1. Determination of colouring components and coloured thermal degradation products by high-performance liquid chromatography with photodiode array detection. Journal of Agricultural and Food Chemistry, 46: 1031-1038.

Silva, G. F., Gamarra, F. M. C., Oliveira, A. L. and Cabral, F. A. (2008). Extraction of bixin from annatto seeds using supercritical carbon dioxide. Brazilian Journal of Engineering Chemical, 25(02): 419 - 426.

Swati, D., Manisha, S., Sonia S., Kanade P. M., Dhiraj P., Ganesh N. (2013). Formulation and evaluation of natural lipsticks prepared from Bixa orellana seeds and Beta vulgaris root extract and their comparative study. International Journal of Pharmacy and Pharmaceutical Sciences, 5(4): 68-70.

Verissimo, S. A., Oliveria, E. L., Ladchunmananandasivam, R., Cruz, L.R.P., Praxedes, G. F. and Aquino, M. S. (2003). Extraction, characterization and application of annatto's dye in the dyeing of natural fibres. The sixth Italian conference on chemical and process engineering. 1635-1640. 